\title{
Novel Co-Precipitation Method for Synthesis of Nanostructured Nickel Oxide in Accordance to PH: Structural and Optical Properties as an Active Optical Filter
}

\author{
Zehraa N. Abdul-Ameer \\ Lecturer Remote Sensing and GIS dept. / College of science/ university of Baghdad, Baghdad, Iraq. \\ zehraanajim@gmail.com
}

Article history: Received in:2October2018, accepted in:6 November 2018, Publish January, 2019

\begin{abstract}
Low cost Co-Precipitation method was used for Preparation of novel nickel oxide (NiO) nano particle thin films with Simple, with two different PH values 6, 12 and its effect on structural and optical properties as an active optical filter. Experimental results of structural properties X-ray diffraction (XRD) showed that both Nickel oxide nanoparticles with $(\mathrm{PH}=6$ and 12) have polycrystalline structure smaller average particle size about $8.5 \mathrm{~nm}$ for $\mathrm{PH}=6$ in comparison with $\mathrm{PH}=12$. Morphological studies using Scanning electron microscopy (SEM) and atomic force microscope (AFM) show uniform nano rod distribution for $\mathrm{PH}=6$ with smaller average diameter, average roughness as compared with $\mathrm{NiO}$ with $\mathrm{PH}=12$ that showed larger diameter, grain size, spherical shape with scope of excellent sensing applications due to high roughness. Optical properties results show blue shift for $\mathrm{PH}=6$ as compared with $\mathrm{PH}=12 \mathrm{~m}$ leading to potential of optoelectronic applications and as active optical
\end{abstract}

Keywords: Nickel Oxide, Co-precipitation method, PH, particle size, nanostructure.

\section{Introduction}

Nickel oxide is considered a unique p-type semiconductor due to its structure of defects, and special properties [1]. NiO attracted Researchers interest for the potential use in several applications such as: magnetic materials, gas sensors, and fuel cells [2]. Many techniques have been used for fabrication of $\mathrm{NiO}$ nano particles such as: sol-gel method [3], spray pyrolysis [4], thermal decomposition [5] Ultrasonic radiation [6], hydrothermal synthesis [7]. The aim of this research is synthesized nickel oxide nano particles in two different $\mathrm{PH}$ then study its effect on nano particle size, structure and optical properties.

\section{Experimental Methods}

Two solutions of $0.01 \mathrm{M} \mathrm{Ni}\left(\mathrm{NO}_{3}\right)_{2} \cdot 6 \mathrm{H}_{2} \mathrm{O}$ were solute in $100 \mathrm{ml}$ Double deionized water with continuous stirring for 10 min then: first solution was added to $(0.1 \mathrm{M}) \mathrm{NaOH}(\mathrm{PH}=12)$, second solution was added to $(0.05 \mathrm{M}) \mathrm{NaOH}(\mathrm{PH}=6)$. the followed by drying in $120^{\circ} \mathrm{C}$ for 6 hours. Calcination process occurred at $450^{\circ} \mathrm{C}$ for 4 hours. Sampled were deposited on glass for further characterization of X-ray diffraction (XRD) with $\mathrm{CuK} \alpha$ radiation $\left(\lambda=1.5405^{\circ} \mathrm{A}\right)$ to investigate crystallite size. 


\section{Results and Discussion:}

\subsection{Structural Properties:}

Figure 1. shows $x$-ray diffraction pattern with five peaks with preferential orientation $2 \theta=43.4^{\circ}$ and cubic phase. XRD peaks are $2 \theta=37.2^{\circ}, 43.4^{\circ}, 62.8^{\circ}$, $75.4^{\circ}, 79.6^{\circ}$ JCPDS card [file number: 4-0835] [8]. Particle sizes can be calculated due to Debye-Sheerer formula:

$D=0.9 \frac{\lambda}{\operatorname{COS} \theta}$

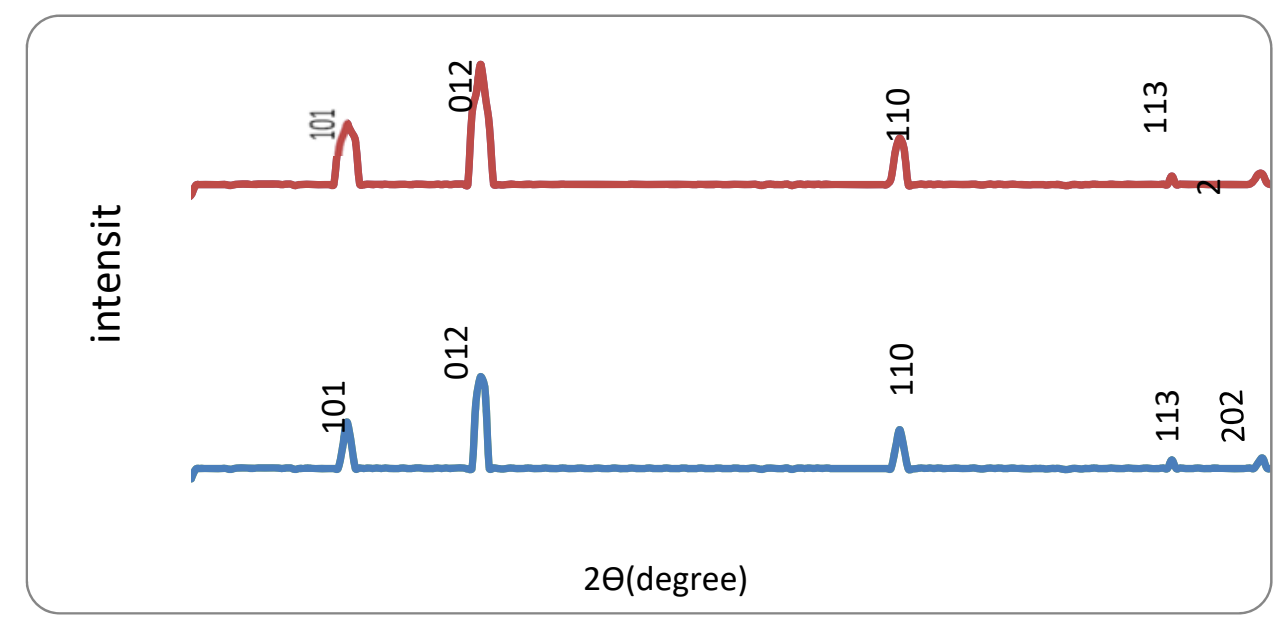

Figure 1. XRD pattern for the prepared sample.

Table 1. illustrate the comparison of Nickel oxide with $\mathrm{PH}=6$ and $\mathrm{PH}=12$. Nickel oxide with $\mathrm{PH}=6$ has smaller particle size about $8.5 \mathrm{~nm}$ while Nickel oxide with $\mathrm{PH}=12$ has greater particle size about $20 \mathrm{~nm}$. both have polycrystalline structure.

Table 1. XRD parameters for the prepared samples

\begin{tabular}{|c|c|c|c|c|c|}
\hline Sample & $\beta(\mathrm{rad})$ & $\mathrm{D}(\mathrm{nm})$ & $\begin{array}{c}\varepsilon \\
\left(* 10^{-3} \text { lines }^{-2} \mathrm{~m}^{-4}\right)\end{array}$ & $\Delta$ & hkl \\
\hline $\begin{array}{c}\mathrm{NiO} \\
(\mathrm{PH}=6)\end{array}$ & 0.98 & 8.5 & 3.97 & 0.013 & $\begin{array}{l}101 \\
012 \\
110 \\
113 \\
202\end{array}$ \\
\hline $\begin{array}{c}\mathrm{NiO} \\
(\mathrm{PH}=12)\end{array}$ & 0.52 & 20 & 2.1 & 0.0025 & $\begin{array}{l}101 \\
012 \\
110 \\
113 \\
202\end{array}$ \\
\hline
\end{tabular}


The SEM images for NiO nano particles is shown in Figure 2. to investigate surface morphology of the synthesized samples $\mathrm{NiO}$ nano particles with $(\mathrm{PH}=6)$ showed uniformly distributed nano rod shapes While $\mathrm{NiO}$ nano particles with $(\mathrm{PH}=12)$ have spherical shapes with some agglomeration due to tendency to have high surface energy. It is concluded that $\mathrm{NiO}$ nano particles with $(\mathrm{PH}=6)$ had smaller particle size in comparison with $\mathrm{NiO}$ nano particles with $(\mathrm{PH}=12)$ with uniform distribution of nano rods which encourage catalytic activity of nano particles. AFM analysis showed high average roughness $(1.94 \mathrm{~nm})$ for $\mathrm{NiO}$ nano particles with $(\mathrm{PH}=12)$ in comparison with $\mathrm{NiO}$ nano particles with $(\mathrm{PH}=6)$ which were $(0.995 \mathrm{~nm})$ as shown in Figure 3.
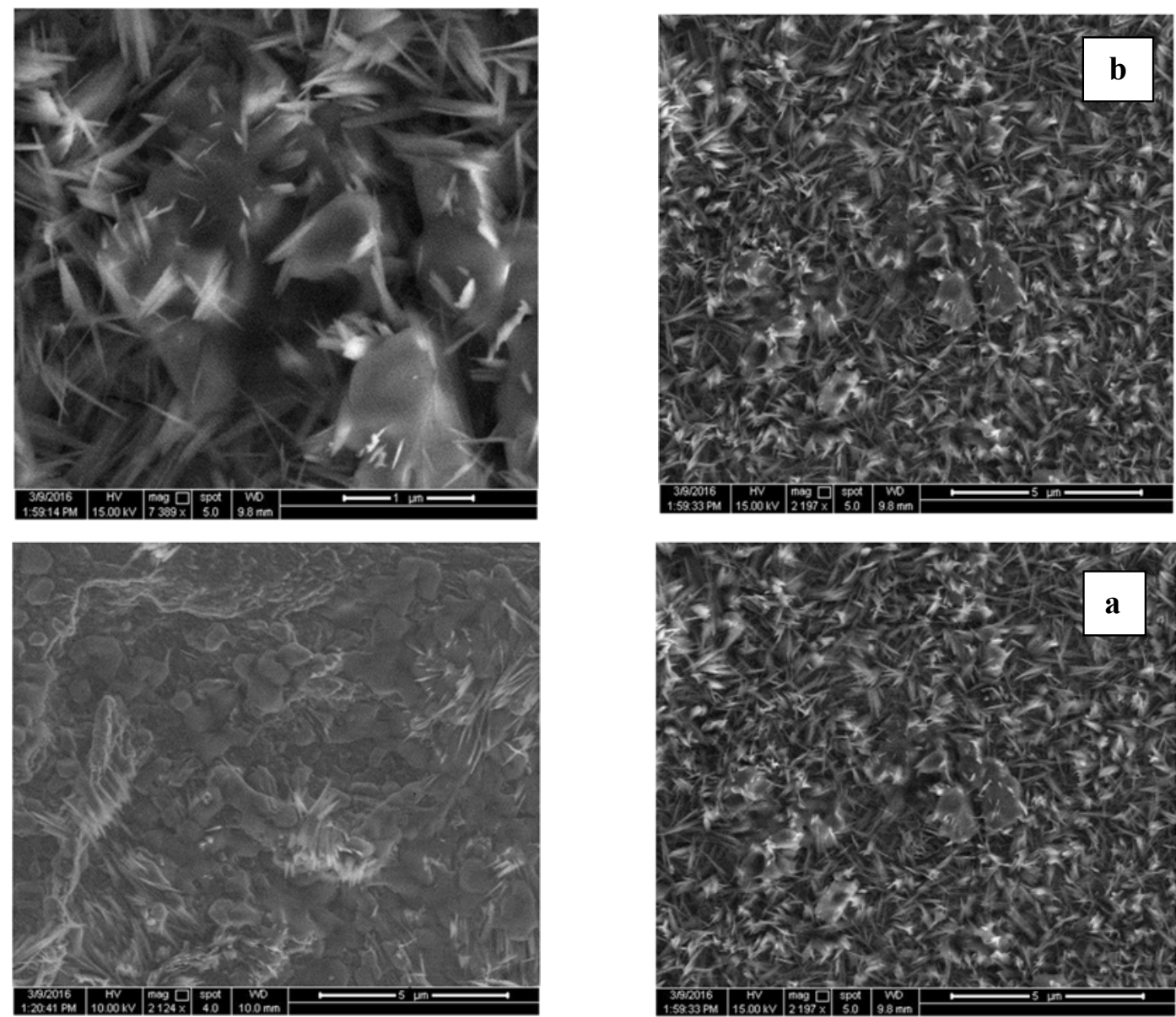

Figure 2. SEM images for a- $\mathrm{NiO}$ nanoparticles $(\mathrm{PH}=6)$ and $\mathrm{b}-\mathrm{NiO}$ nanoparticles with $(\mathrm{PH}=12)$.

The UV-V is characterization spectrum was investigated to calculate optical Energy gap. It was found that absorption peak from UV absorption spectrum was about $348 \mathrm{~nm}$ with blue shift in comparison with bulk $\mathrm{NiO}$. The calculated band gaps for $\mathrm{NiO}$ with $(\mathrm{PH}=6)$ was $(4 \mathrm{eV})$ while $\mathrm{NiO}$ with $(\mathrm{PH}=12)$ was $(3.83 \mathrm{eV})$ as shown in Figure 4. It can be due to larger particle size for $\mathrm{NiO}$ with $(\mathrm{PH}=12)$ compared with $\mathrm{NiO}$ with $(\mathrm{PH}=6)$. Equation (2). was used to calculate energy gap using $[1,9,10]$ :

$$
\alpha \boldsymbol{h} v=A(\boldsymbol{h} v-E g)^{n}
$$

Where A is constant related with inter band probability, Eg is referred to optical energy gap and $\mathrm{n}$ is characteristic for the nature of transition process where $\mathrm{n}=2$ (direct transition) [12]. 


(Uj)
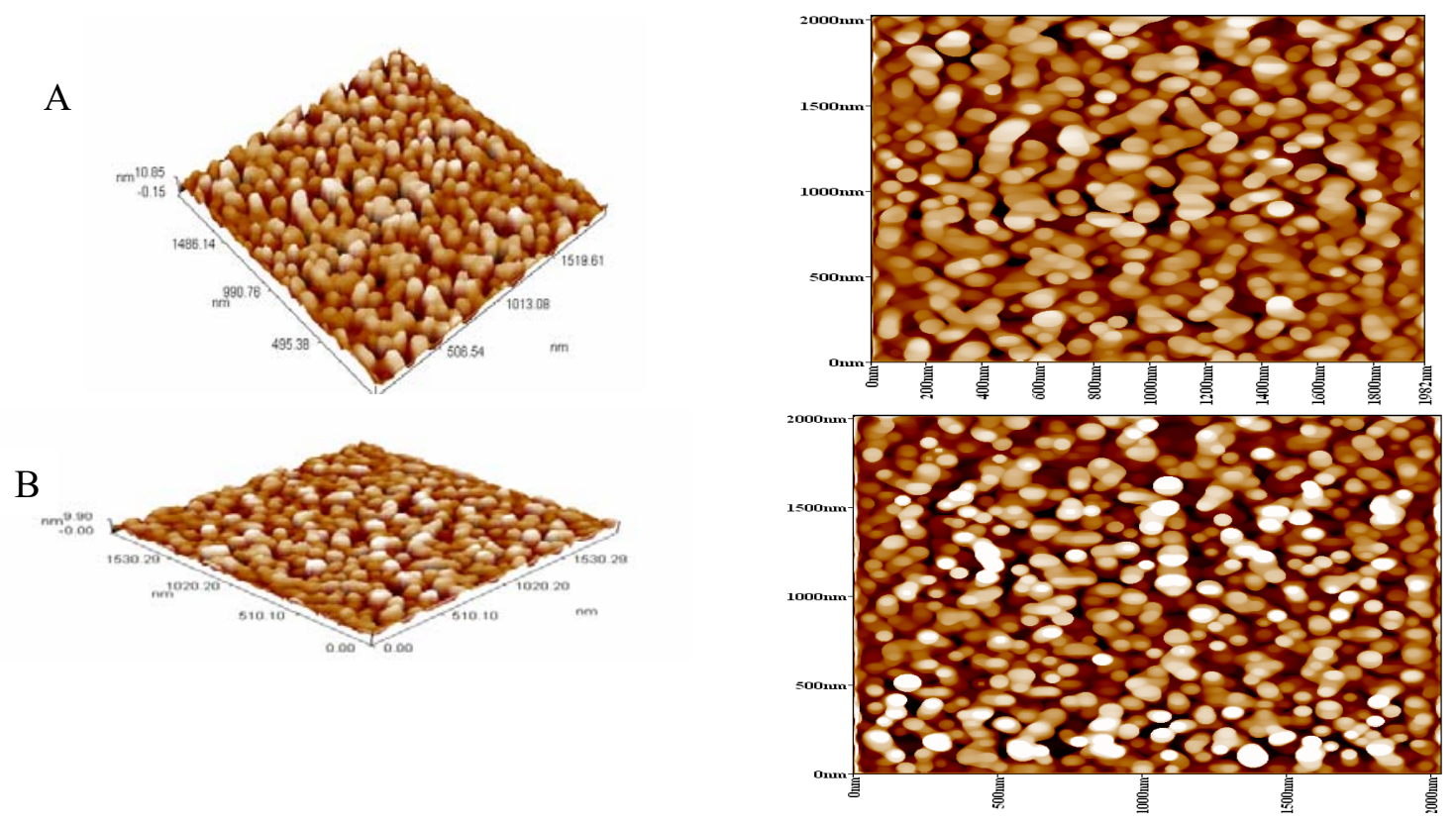

Figure 3. $\mathrm{AFM}$ images a- $\mathrm{NiO}$ nanoparticles with $(\mathrm{PH}=6)$ and $\mathrm{b}-\mathrm{NiO}$ nanoparticles with $(\mathrm{PH}=12)$.

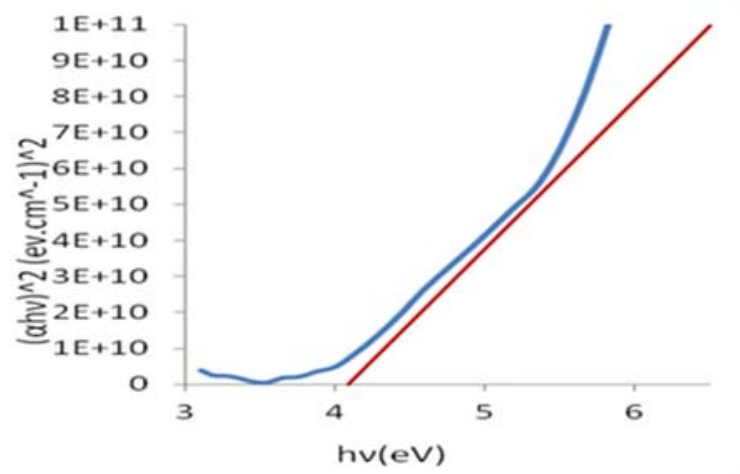

a
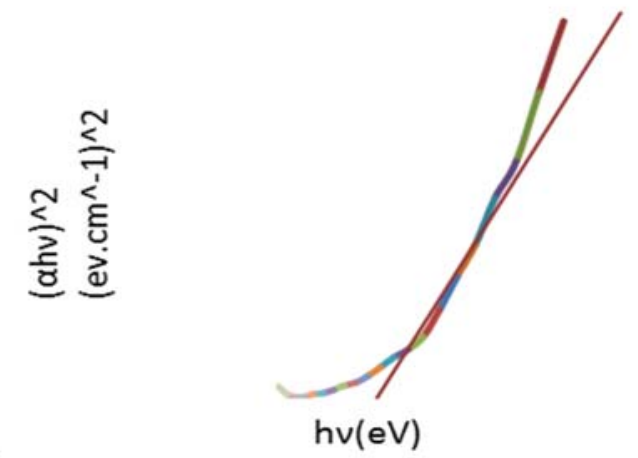

B

Figure 4. $(\alpha h v)^{\wedge} 2$ as function of $(h v)$ for a- $\mathrm{NiO}$ with $\mathrm{PH}=6$ and $b-\mathrm{NiO}$ with $\mathrm{PH}=12$.

Table 2. AFM surface analysis.

\begin{tabular}{ccc}
\hline \hline $\mathrm{PH}$ & Average Roughness (nm) & Root mean square (r.m.s) (nm) \\
& & \\
\hline \hline & & \\
$\mathrm{PH}=6$ & 0.995 & 1.17 \\
$\mathrm{PH}=12$ & 1.94 & 2.38 \\
& & \\
\hline \hline
\end{tabular}




\section{Conclusions}

Nickel Oxide nano particles were synthesized using Co-Precipitation method with two different $(\mathrm{PH}=6$ and 12) to investigate $\mathrm{PH}$ effect on size and shape of nano particles. XRD results indicate that Nickel oxide with $(\mathrm{PH}=6$ and 12) have polycrystalline structure smaller average particle size about $8.5 \mathrm{~nm}$ for $(\mathrm{PH}=6)$ win comparison with $\mathrm{PH}=12$.UV-VIS spectrum Showed blue shift for $(\mathrm{PH}=6)$ as compared with $(\mathrm{PH}=12)$. SEM and AFM Morphological studies showed uniform nano rod distribution for $(\mathrm{PH}=6)$ with smaller average diameter and average roughness as compared with $\mathrm{NiO}$ with $(\mathrm{PH}=12)$. This study enhances the idea of use $\mathrm{NiO}$ nano particles for different and wide range applications according to $\mathrm{PH}$ values in various industries.

\section{Literature Contribute}

This study attract attention on nickel oxide nano particles synthesized in simple, low cost, friendly method with two $\mathrm{PH}$ values $=6,12$. Uniform nano rod with blue shift spectra obtained from $\mathrm{NiO}$ nano particles with $\mathrm{PH}=6$ e emitters, catalyst, $\mathrm{NiO}$ nano particles with $\mathrm{PH}=6$ possessed rough surface which enhance gas sensing applications.

\section{Conflict of Interest}

Dr-zehraa najim declare that there is no conflict of interest.

\section{References}

1. Devi, B.S.R.; Raveendran,R.; Vaidyan, A.V., J. Pramana. Synthesis and characterization of Mn2+-doped $\mathrm{ZnS}$ nanoparticles. Pramana - Journal of Physics. 2007, 68, 4, 679-687.

2. Din, M. I.; Rani, A. Recent Advances in the Synthesis and Stabilization of Nickel and Nickel Oxide Nanoparticles: A green Adeptness, International Journal of Analytical Chemistry. 2016, 4, 1-14, doi.org/10.1155/2016/3512145.

3. El-Kemary,M.; Nagy,N.; El-Mehasseb, I. Nickel Oxide nanoparticles: Synthesis and spectral studies of interactions with glucose.Materials Science in Semiconductor Processing. 2013, 16, 6, 1747-1752.

4. Han, D.Y.; Yang, H.Y.; Shen, X.; Zhou,C.B. ; Wang F.H., Synthesis and size control of Nio Nanoparticles by water- Powder-In-Oil Microemulsion. Powder Technology Powder Teach. Elsevier. 2004. 147, 1-3,113-116.

5. Ravindhranath,K; Ramamoorty,M. Nickel Based Nano Parles as Adsorbents in Water Purification Methods - A Review. Orient J. Chem. 2017, 33, 4, 1603-1613.

6. Palombari, R. Influence of surface acceptor-donor couples on conductivity and other electrochemical properties of nonstoichiometric $\mathrm{NiO}$ at $200{ }^{\circ} \mathrm{C}$. J. Electroanal. Chem. 2003. 546, 23-28.

7. Pulimi, V. R. R.; Jeevanandam,P. Effects of calcinations temperature and precursor concentration on crystallinity of Nio nanocrystalline powder synthesized via Ethylene Glycol rote;Alp conference proceeding. 2009, 321, 2556-2562. 
8. Sang-Jin, L.; Young-Min, H.; Choong-Hwan, J.; Ji-Yeon, K.Nano-Sized Nickel Oxide Powder Synthesized by Organic- Inorganic Solution Route. Journal of Nanoscience and Nanotechnology.2013.13, 2, 1520-1524.

9. Tao, D.; Wei, F. New Procedure towards Size-Homogeneous and Well-Dispersed Nickel Oxide Nanoparticles of 30 nm. Mater. Letts. 2004, 58, 25, 3226-3228 .

10. Teoh, L.G.; Li, K.Synthesis and Characterization of NiO Nanoparticles by Sol Gel Method. Materials Transactions.2012.53, 12, 2135-2140.

11. Visuvasam, A.S.; Dineshbabu, N.R. Study the Structural and Optical Properties of Nickel Oxide Nanoparticles, Inter. J. Adv.Res. 2016.3, 13.

12. Xiang, L.; Deng, X.Y.; Jin,Y. Experimental study on synthesis of NiO nano-particles. Scripta Mater. Elsevier. 2002.47, 4, 219-224. 